AperTO - Archivio Istituzionale Open Access dell'Università di Torino

\title{
Climate change may drive cave spiders to extinction
}

\section{This is the author's manuscript}

Original Citation:

Availability:

This version is available http://hdl.handle.net/2318/1623725

since 2018-01-15T11:05:07Z

Published version:

DOI:10.1111/ecog.02902

Terms of use:

Open Access

Anyone can freely access the full text of works made available as "Open Access". Works made available under a Creative Commons license can be used according to the terms and conditions of said license. Use of all other works requires consent of the right holder (author or publisher) if not exempted from copyright protection by the applicable law. 


\section{Climate change may drive cave spiders to extinction}

Stefano Mammola ${ }^{1,2}$, Sara L. Goodacre ${ }^{3}$ and Marco Isaia ${ }^{1,2}$

${ }^{1}$ Department of Life Sciences and Systems Biology, University of Torino, Torino, Italy

${ }^{2}$ IUCN SSC Spider \& Scorpion Specialist Group, Torino, Italy

${ }^{3}$ School of Biology, University of Nottingham, Nottingham, UK

Corresponding author: Marco Isaia, Department of Life Sciences and Systems

Biology, University of Torino, Torino, Italy . E-mail: marco.isaia@ unito.it. Tel: 011 6704544; Fax: 0116704508

Decision date: 18-Jan-2017

This article has been accepted for publication and undergone full peer review but has not been through the copyediting, typesetting, pagination and proofreading process, which may lead to differences between this version and the Version of Record. Please cite this article as doi: [10.1111/ecog.02902]. 


\section{Abstract}

Subterranean ecosystems present ideal opportunities to study mechanisms underlying responses to changes in climate because species within them are often adapted to a largely constant temperature. We have characterized the thermal conditions of caves in the Western Alps, and related these hypogean climate data to the occurrence of Troglohyphantes spiders (Araneae, Linyphiidae). Our data indicated that present distributions reflect Pleistocene glaciation events and also pointed to specific responses as a consequence of changes in temperature. Constant temperatures recorded inside caves provide an approximation of the mean annual temperature outside, thus we extended the results to a regional scale. We used ecological niche modeling to predict habitat suitability both in the Pleistocene and under future global warming scenarios. These analyses pointed toward a future decline in habitat suitability for subterranean spiders and the potential extinction of the most restricted endemic species. When compared with other species that live in confined habitats such as islands and mountains, we expect cave species to be as much, if not more, vulnerable to climate change.

Keywords: Subterranean biology, Ecological Niche Modeling, Local extinction, Global Warming, Pleistocene glaciation, Araneae, Troglohyphantes, MaxEnt 


\section{Introduction}

The potential impact of global climate change on a broad range of organisms occurring in different ecosystems and showing a very diverse pattern of distributions is well documented (Walther et al. 2002, Parmesan and Yohe 2003, Parmesan 2006, Walther 2010, Chen et al. 2011, Dawson et al. 2011, Bellard et al. 2012). However, the effects on biological communities in hypogean ecosystems have not been well explored (but see Brandmayr et al. 2013, Wynne et al. 2014, Sánchez-Fernández et al. 2016).

From an ecological standpoint, hypogean ecosystems are considered extreme, lacking solar radiation, receiving poor energy inputs, and through being characterized by low abundance and diversity of organisms (Poulson and White 1969, Culver and Pipan 2009, Romero 2009). Most caves have almost constant temperature over the year, with an annual variability decreasing progressively with increasing distance from the entrance until a remarkable temperature steadiness is reached (Moore and Sullivan 1964, Smithson 1991), usually varying by only a few tenths of a degree over the year (Badino 2010).

According to direct field observations (Fejér and Moldovan 2013, Domìnguez-Villar et al. 2015) and theoretical models (Badino 2004, Covington and Perne 2015), anthropogenic global warming may significantly influence and modify the underground climate in different ways to that which happens outside. The most important difference refers to the thermal inertia of caves, which explains time lags of up to several decades in the warming of the system (Badino 2004). This increased flux of energy from the atmosphere to the subterranean environment is expected to be deposited primarily in the superficial sections of caves (Badino 2004) and in other superficial subterranean habitats (Mammola et al. 2016). Energy fluxes accumulating underground may have dramatic cascade effects on both physical and biological components of hypogean ecosystems. By affecting air density gradients, for instance, small changes in cave temperature modify air circulation, with potential fallouts on speleothem growth, 
seasonal ventilation rates, and processes of condensation and corrosion (DomìnguezVillar et al. 2015).

Given the reduced physiological tolerance to temperature fluctuations in subterranean species (e.g. Bernabò et al. 2011, Mermillod-Blondin et al. 2013, Novak et al. 2014, Rizzo et al. 2015) as well as their low dispersal capacity (Sánchez-Fernández et al. 2016), ongoing human-driven climatic shifts are also expected to affect subterranean biocoenosis and ecosystems (Wynne et al. 2014). From a conservation perspective, the ecological and biogeographical peculiarity of the subterranean fauna enhances the risk of local extinction (Cardoso 2011a, b, 2012) and strengthens the importance of considering subterranean organisms as model species for ecological studies dealing with climatic changes (Chevaldonné and Lejeune 2003, Wynne et al. 2014, Mammola et al. 2015b).

We investigated the response of hypogean specialized spiders to increases in temperature in the Western sector of the Alps. Among the range of subterranean taxa occurring in the Western Alps, we chose the cave-dwelling spiders Troglohyphantes (Araneae, Linyphiidae) as model organisms. The reliability of this model comes from empirical observations pointing out their preference for narrow, stable and cool microclimatic conditions (Deeleman-Reinhold 1978, Isaia and Pantini 2010, Isaia et al. 2011, 2017, Mammola and Isaia 2016). Accordingly, Troglohyphantes spiders are characterized by moderate to high levels of troglobiomorphy (sensu Juberthie and Decu 1994) and show restricted or point-like ranges of distribution (e.g. Brignoli 1971, Deeleman-Reinhold 1978, Isaia and Pantini 2010, Isaia et al. 2011). On top of that, populations of Troglohyphantes are usually extremely structured from a genetic point of view, lacking shared haplotypes between caves and showing highly reduced dispersal ability (Mammola et al. 2015a). 
We modelled presence/absence of Troglohyphantes spiders in relation to cave microclimate, past glacial dynamics and other cave features in order to assess their sensitivity to potential subterranean climatic variation induced by climate change. Because constant temperatures recorded inside caves provide an approximation of the mean annual temperature outside (Moore and Sullivan 1964, Smithson 1991, Badino 2004, 2010), in a second step we extended the results to a bigger dataset. We used Ecological Niche Modeling (ENM) to extend to a wider scale the response of our model organism to climatic changes, estimating the impact in terms of loss of habitat suitability. In particular, we hypothesized i) a significant relationship between the occurrence of Troglohyphantes spiders and different climatic conditions as a function of their adaptation to narrow and specific ranges of temperature; and ii) that climate affected the distribution of our model species in the past and will affect it in the future, through a decline in habitat suitability.

\section{Materials and methods}

\section{Study area}

We studied caves in the administrative regions of Piemonte and Valle d'Aosta (Western Alps, Italy), a coherent biogeographic area of the Alps in which the distribution of Troglohyphantes spiders has been well documented (e.g. Isaia and Pantini 2010, Isaia et al. 2011, 2017). We used a regional scale for analyses instead of smaller or larger scales, as the former has been shown to be appropriate for species-level responses to global warming (Walther et al. 2002). The Western Alps contain more than 2,500 caves developed in carbonate and non-carbonate substrates (AGSP, 2016), plus a variety of artificial hypogean habitats such as bunkers and abandoned mines.

We selected 33 hypogean localities over a north-south range in the Western Alps (Fig. 1), from the Tanaro Valley (South; Province of Cuneo) to the Strona Valley (North; Province of Verbania). These included karst and tectonic caves as well as artificial 
subterranean sites, with an altitudinal range of 415-2,357 $\mathrm{m}$ a.s.1, a planimetric development range of 7-3,440 $\mathrm{m}$ and an ascending/descending structure (i.e. drop) range from -143 to $+184 \mathrm{~m}$. We deliberately choose localities with an established, recently and well-documented spider fauna (see Isaia et al. 2011). A description of each site is provided in Supplementary Material Appendix 1.

\section{Sampling design}

Temperature (T) was monitored from 2012 to 2014 using Hygrochron ${ }^{\mathrm{TM}}$ devices (accuracy: $\pm 0.5{ }^{\circ} \mathrm{C}$ ) placed inside the cave $\left(\mathrm{T}_{\mathrm{int}}\right)$ and at cave entrances $\left(\mathrm{T}_{\text {ext }}\right.$ ). Measurements were taken every 3 hours and the devices were replaced after 12 months to allow download of data part way through the study.

The presence of Troglohyphantes at each site was verified during all surveys. The final presence/absence dataset was verified and integrated with available literature data (Isaia and Pantini 2010, Isaia et al. 2011, 2017), wherever possible.

\section{Fine-scale modeling}

Data from the Hygrochron ${ }^{\mathrm{TM}}$ devices were used to generate values of mean annual temperature, daily and annual range at the cave entrance $\left(\mathrm{T}_{\text {ext }}\right)$ and at the deeper zone $\left(\mathrm{T}_{\mathrm{int}}\right)$. Sites were sorted according to previous glacial history (ICE), as identified through an in-field geological survey by Motta (2014) or by using paleo-glacial reconstruction for sites not included in the Motta study (Ehlers et al. 2011) - see Supplementary Material Appendix 1. The relationship between temperature variables was explored using linear regression models — $I m$ command in the "stats" $\mathrm{R}$ package $(\mathrm{R}$ Development Team 2015). Presence/absence of spiders was modelled as a function of temperature and the glacial history (ICE) via generalized linear models ( $\mathrm{glm}$ command in the "stats" $\mathrm{R}$ package) assuming a Bernoulli error structure (0-1 discrete). Prior to 
model fitting, we tested for multi-collinearity among covariates and excluded collinear variables (Zuur et al. 2010). We tested for spatial autocorrelation among environmental variables and in species occurrence via Moran's I test in the "ape" R package (Paradis et al. 2004), using the Gittleman and Kot (1990) method. After fitting the initial model, we carried out model reduction by sequentially deleting terms-backward eliminationaccording to AICc values (Hurvich and Tsai 1989). The process was repeated until a minimum adequate model of fixed effects remained (Zuur et al. 2009).

\section{Wide scale modeling, past and future predictions}

Once the model had been fitted using the fine-scale dataset, we extended the detected trends to a wider scale—regional—using ecological niche modeling. We modelled the current distribution of Troglohyphantes in the study area, transferring the results into ancestral (Last Glacial Maximum; 22,000 years ago; hereinafter LGM) and future (2050 and 2070) climatic conditions in order to estimate variations in the distribution ranges relative to past and future climate changes.

\section{Occurrence points}

Geo-referenced occurrence localities of Troglohyphantes spp. were taken from Isaia et al. (2011) and Isaia et al. (2017). This dataset covers 361 caves and virtually all possible thermal ranges experienced by Troglohyphantes spiders in the Western Alps. T. lucifuga and T. lucifer, which are not exclusively restricted to subterranean habitats (Isaia and Pantini 2010, Isaia et al. 2017), were excluded from our analysis. Prior to model fitting, we designated a sampling bias grid (Phillips et al. 2009, Syfert et al. 2013). Within each cell in the grid — which had a width equal to the grain of the bioclimatic rasters — all the points apart from one were randomly removed (see Newbold 2010). In this way, we 
minimised spatial autocorrelation, given that proximate localities likely comprise similar environmental variables.

\section{Explanatory variables}

We represented present-day climate with 19 bioclimatic variables (1950-2000; Hijmans et al. 2005; resolution: 30"; available at: www.worldclim.org; Table 1), and analogous data layers for past and future climate. For both past and future climate, multiple GMCs were used to take into account variation and uncertainty among simulations (Kageyama et al. 2001, Beaumont et al. 2008, Diniz-Filho et al. 2009). Paleo-bioclimatic variables for the LGM were derived from simulations available from three General Circulation Models (GCMs) from the Coupled Model Intercomparison Project Phase 5 (CMIP5; Taylor et al. 2012). These were CCSM4, MIROC-ESM and MPI-ESM-P (resolution of 2.5'). Future data represent downscaled and calibrated climate projections from three GCMs (CCSM4, BCC-CSM1-1, MIROC5) under two Representative Concentration Pathway scenarios (rcp 2.6 and rep 8.5 respectively) for both 2050 and 2070, at a resolution of 30". Ice cover during Pleistocene was derived from paleo-reconstruction, by converting the shape of glacial masses provided by Ehlers et al. (2011) into a binary raster. This categorical variable was further included in the models. Prior to model computing, we investigated multi-collinearity among covariates via Pearson $r$ correlation (Zuur et al. 2009, 2010), selecting a final set of uncorrelated bioclimatic variables $(r< \pm 0.7)$ (Table 1$)$.

\section{Algorithm choice and projections}

A wide suite of algorithms exists in the realm of bioclimatic envelope modeling (Peterson et al. 2011). Considering the conceptual ground of the "no free lunch" theorem (Ho and Pepyne 2002), Qiao et al. (2015) recently suggested that no single best 
algorithm should be chosen a priori for modeling the ecological niche/species distribution of a certain organism. We thus began the analysis of this particular dataset with an assessment of performance of potential competing algorithms (see also Elith et al. 2006). In particular, we tested the performance of three well-acknowledged statistical techniques, belonging to the three existing categories of algorithms for computing ENM/SDM: regression [Generalized linear models (GLM); McCullagh and Nelder 1989], regression trees [Boosted Regression Trees (BRT); Friedman, 2001] and machine-learning [Maximum entropy model (MaxEnt); Philips et al. 2006]. Details of the modeling procedure and settings for each technique are provided in Supplementary Material Appendix 2.

As is widely recommended in the literature (e.g. Peterson et al. 2011, Saupe et al. 2012, Merow et al. 2013), models were calibrated within the accessible area-often referred to as area M (Barve et al. 2011; details in Supplementary Material Appendix 2). M is the geographic extent hypothesized to fall within the long-term dispersal and colonization potential for a particular species over its evolutionary history. Considering the reduced dispersal potential of Troglohyphantes spiders, in our case area M was approximated by masking the bioclimatic layers with a rectangle delimiting the Western alpine chain.

We computed the models using the three modelling techniques in order to relate the occurrence points to the set of non-collinear variables. For each technique, we ran twenty replicate of models, keeping a random partition of $20 \%$ of the points for each run to assess the predictive ability of each algorithm. Predictive abilities of the three models were obtained by calculating two different metrics (average of the twenty runs): the area under the Receiver Operating Characteristics (ROC) curve (AUC; Fielding and Bell 1997) and the True Skill Statistics (TSS; Allouche et al. 2006), whereby an AUC < 0.60 and/or a TSS $<0.1$ denotes a predictive ability no better than random. We 
employed two metrics because it is not recommended to rely on a single measure of model fit for comparing different techniques (Elith and Graham 2009).

We finally retained the modeling technique showing the best performance. A final model was generated using the same parameters and calibrated with the complete occurrence dataset. Subsequently, we transferred the model into each LGM and future GCMs, and we calculated the median value across all projections for each combination of GCM. We used a conservative approach to estimate habitat suitability, by applying a threshold of 0.4 to the continuous probability surface of presence estimated after the projections. Areas below a threshold value of 0.4 were set to 0 .

\section{Results}

\section{Fine-scale modelling}

As expected, we observed a strong linear relationship between mean annual $\mathrm{T}_{\text {int }}$ and mean annual $\mathrm{T}_{\text {ext }}$ (Estimated $\beta \pm$ se: $0.901 \pm 0.041, \mathrm{p}<0.001$ ), with only 3 out of 33 caves showing $\mathrm{T}_{\text {int }}$ values $>1{ }^{\circ} \mathrm{C}$ higher (Grotta di Bergovei and Fessura di Verrogne) or lower (Grotta Testa di Napoleone) than $\mathrm{T}_{\mathrm{ext}}$ values (Supplementary material Appendix 2, Fig. A1).

No variables considered in the GLM analysis were found to be spatially autocorrelated (Moran's I test, all $p>0.05)$ apart from the mean annual $\mathrm{T}_{\text {int }}$ range $(\mathrm{p}<0.01)$ which was therefore not considered further. Moran's I test results are reported in the Supplementary Material Appendix 2, Table A1. Daily range of $\mathrm{T}_{\text {int }}$ was highly collinear with past ice cover (ICE) and thus excluded from the analysis (Supplementary material Appendix 2, Fig. A2). All variables related to $\mathrm{T}_{\mathrm{ext}}$ (mean and range) were highly collinear with $\mathrm{T}_{\text {int }}$ (Pearson $r> \pm 0.7$ ), and thus not included in the model (Supplementary material Appendix 2, Table A2). Backward elimination revealed that variables related to cave features-type of cave, total development, drop-were not influential in 
determining the presence/absence of Troglohyphantes and these were therefore not considered in further analytical steps. Accordingly, the structure of the minimum adequate model included mean annual $\mathrm{T}_{\text {int }}$ and the past glacial cover (ICE) as covariates. Outcomes of the GLM pointed to a significant decrease in the probability of occurrence of Troglohyphantes with increasing mean annual $\mathrm{T}_{\text {int }}$ values (Estimated $\beta \pm$ se: $\quad-0.543 \pm 0.249, \mathrm{p}=0.02)$. We also found a significant negative effect of glacial history, namely a lower probability of occurrence of the model organisms in caves covered by the ice during past glaciations (ICE, test relative to the level "uncovered"; Estimated $\beta \pm$ se: $-2.584 \pm 1.052$, $\mathrm{p}=0.01$; Fig. 2).

\section{Model on the regional dataset, past and future predictions}

MaxEnt performed better than other algorithms tested in terms of predictive ability (MaxEnt: mean AUC $\pm \mathrm{sd}=0.873 \pm 0.09 ;$ mean TSS $\pm \mathrm{sd}=0.51 \pm 0.08 ; \mathrm{GLM}: \mathrm{AUC} \pm \mathrm{sd}=$ $0.676 \pm 0.378$; mean $\mathrm{TSS} \pm \mathrm{sd}=0.32 \pm 0.221 ; \mathrm{BRT}: \mathrm{AUC} \pm \mathrm{sd}=0.78 \pm 0.02 ; \mathrm{TSS} \pm \mathrm{sd}=$ $0.43 \pm 0.12)$. We therefore retained the former technique for further analysis and projections. Uncorrelated variables introduced in the final model are reported in Table

1. The final model included mean annual temperature (Bio01), mean diurnal range (Bio02), and ice cover (ICE)—response plots are reported in Supplementary Material Appendix 2, Fig. A3. Suitable areas predicted by the model for the current climate (Fig. 3) roughly overlay the known distribution of Troglohyphantes in the study area, with higher suitability predicted in the low-medium mountain belt, ranging from the districts of Maritime to Graian Alps. The most suitable and unfragmented habitat is found at the southern border of the Alps. Based on the model projections, the average decline in the probability of occurrence is 0.68 across all known populations of Troglohyphantes. With regard to LGM projections (Fig. 3), the district of Maritime Alps (South-western Alps) and the surrounding plains appear to contain the most suitable areas of habitat. 
Areas covered by ice were predicted to be largely unsuitable, with areas bordering the glacial masses possibly acting as microrefugia (sensu Rull 2009).

Future forecasts based on different emission scenarios indicate a general decline of suitability throughout the distribution range (Fig. 4). For 2050 we predict a general decrease in suitable habitat (threshold 0.4 ) of $~ 45 \%$ for the low emission (rcp 2.6) and of $\sim 55 \%$ for the high emission scenario (rcp 8.5) in respect with the present-day projection. Habitat loss is further intensified in the 2070 high-emission scenario, with an overall reduction of $\sim 70 \%$. The predicted loss of suitable habitat appears to be more intense at lower altitudes. In particular, for the high-emission scenario in 2070 approximately half of the current localities are predicted to be unsuitable (Fig. 5). Across all known populations, the average decrease in the probability of occurrence of Troglohyphantes drops from 0.68 to 0.51 in the low emission scenario (both 2050 and 2070). For the high emission scenario, the probability of occurrence drops to 0.40 for 2050 and 0.17 for 2070. 


\section{DISCUSSION}

\section{Caves as laboratories for the study of climate change}

In contrast to fluctuating surface temperatures, temperature stability in the subterranean domain allows the detection of temperature changes over longer time periods. Indeed, this working hypothesis provides a stimulating starting point for the ecological modeling of hypogean ecosystems. In spite of that, correlative distribution modelling techniques have been rarely_and only recently — applied to these particular biological systems (e.g., Bryson et al. 2014, Naranjo et al. 2014, Fišer et al. 2015, Mammola et al. 2015a, Soto-Centeno et al. 2015, Christman et al. 2016, Copper-Bohannon et al. 2016, Ferreira et al. 2016, Sánchez-Fernández et al. 2016).

The link between the external climate and the subterranean habitat has been documented in speleological literature (Moore and Sullivan 1964, Smithson 1991, Badino 2004, 2010, Covington and Perne 2015). The general explanation for this relationship is found in the physics of the infiltrating meteoric fluids. Over a geological timeframe, a given rock layer will be forced to the thermal equilibrium of the water flowing through it. As a consequence, the temperature of the rock surrounding the cave equilibrates to the mean temperature of the infiltrating waters, which, in turn, is equal to the mean temperature outside (Badino 2010). Depending on the thickness of the rock layer (i.e. the cave depth), the amplitude of the sinusoidal input signal (i.e. the external temperature range) can be shifted in time-i.e. there is a time lag between input and output maxima (Badino 2004), but this lag is likely to have a duration of decades. As an example, for the Postojna cave (Slovenia) Domìnguez-Villar et al. (2015) estimated a warming time lag of $\sim 20$ years. In practical terms, this implies that our future projections are mostly relevant for the superficial subterranean habitat-including the outermost sectors of caves - whereas they should be shifted in time of at least 20 years to obtain a more precise time scale for future habitat modifications in deep hypogean layers. In an 
evolutionary sense, such a time lag is not large, but in the time scale of recent global warming it might be significant. As a consequence, spiders that we see today may still be in the lag phase i.e. not yet fully adapted to the current temperature.

We note that, in general, correlative distribution models prioritize the use of extreme values - maxima and minima — instead of average values. Whilst extremes are often believed to reflect a realistic relationship with species-specific physiological constraints (Hijmans et al., 2005), in the case of caves with constant temperatures and reduced temperature excursions, average values are likely to be more appropriate. Our use of average values thus likely increases the robustness of our results because GCMs models are better at predicting average than extreme values (but see Zimmerman et al. 2009).

\section{Interpreting the effects of past climate change}

Two contrasting theories attempt to explain the origin and the distribution of the subterranean fauna (Culver and Pipan 2009, 2010). The theory of the active colonization (Rouch and Danielopol 1987) or adaptive shift hypothesis (Howarth, 1980) puts great emphasis on the process of active colonization of the hypogean domain, with species being driven by the opportunity to occupy new, unexploited ecological niches. On the other hand, the theory of relicts and refuges (Botosaneanu and Holsinger 1991) invokes long-term climatic changes, such as glaciation cycles and other large-scale climate upheavals, as the main factors that prompted the colonization of the subterranean habitat and causing the obliteration of surface-dwelling populations (Holsinger 1988, Botosaneanu and Holsinger 1991).

Although this dichotomous vision exists, the case of our model species possibly supports the latter theory of relict and refuges, given that the occurrence of Troglohyphantes appears to be significantly linked to the glacial history. This pattern can be explained by taking into account the self-evident fact that, most likely, natural 
populations do not survive in caves filled with ice (Culver and Pipan 2010). Remarkably, in our case only two sister species (T. lucifuga and T. lucifer) were found to occur in caves that were covered by ice during the Pleistocene. T. lucifuga is a common and widespread species in the North Western Alps showing a low degree of troglobiomorphism, whereas the recently described $T$. lucifer represents its ecological vicariant in the nearby alpine districts of Cottian and Southern Graian Alps (Isaia et al. 2017). Both species occur in epigean as well as hypogean habitats (Isaia and Pantini 2010, Isaia et al. 2017), an occurrence that could be explained by T. lucifuga and $T$. lucifer having colonized the area after the glaciers retreated.

\section{Global change in hypogean ecosystems}

Little attention has been given to the effects of global climate change on hypogean organisms and ecosystems relative to their epigean counterparts. In this study, we showed the extent to which cave-dwelling biological communities are likely to be affected by changes in temperature. Specialized hypogean arthropods are known to have a fine-tuned thermal tolerance to the constant and narrow temperature ranges of the subterranean habitat (Delay 1978, Huevy and Kingsolver 1989, Lencioni et al. 2010, Bernabò et al. 2011, Novak et al. 2014, Rizzo et al. 2015). However, from a global change perspective, such an adaptation turns out to be a strong limitation. Indeed, while most invertebrates living close to the surface - troglophiles - have retained their ability to withstand temperature variations, many specialized hypogean organismstroglobionts— have lost such thermoregulatory mechanisms (Novak et al. 2014).

Modelling at both local and regional spatial scales indicates that subterranean Troglohyphantes spiders are restricted to particular climatic environments, occurring only in caves with annual mean temperatures below $10-11^{\circ} \mathrm{C}$. This finding implies that in most mid-altitude areas of the W-Alps, where annual mean temperatures are around 
$10-12^{\circ} \mathrm{C}$, populations of Troglohyphantes are close to their physiological limit. Due to predicted temperature rises (IPCC 2014), it is therefore expected that large areas of currently suitable habitat will become progressively unsuitable, therefore falling outside the climatic niche of our model species. Our results, indeed, point to a likely dramatic decline in habitat suitability (Fig. 5) for most of the species included in the analysis $-T$. bornensis, T. iulianae, T. konradi, T. lanai, T. nigraerosae, T. pedemontanus, and $T$. pluto. On the other hand, a higher chance of survival is expected in $T$. vignai because it shows a wider distribution and is also recorded at higher altitudes (above 2,000 m; Isaia et al. 2011, Mammola et al. 2015a). In addition to troglobiomorphic species being restricted to areas of temperature stability, caves are often isolated from each other and species within them, including spiders, often exhibit reduced vagility (e.g., Hedin 1997, Snowman et al. 2010, Yao et al. 2016). In turn, this latter factor significantly increases the threat of global extinction because the rate of recolonisation is low (Cardoso et al. 2011a, b). This is particularly evident for Troglohyphantes spiders, for which we previously demonstrated a very low dispersal ability within caves (Mammola and Isaia 2016) and extreme levels of population differentiation (Mammola et al. 2015a).

It is interesting to note that in the case of other troglobiomorphic species, the assessment of global warming impacts on subterranean species based exclusively on correlative niche models is suggested to be unreliable as species display wider thermal tolerance than reflected by their current distributions (Sánchez-Fernández et al. 2016). Physiological mechanisms that might account for such an observation include the ability to synthesize stress proteins (e.g. heat shock proteins; Bernabò et al. 2011). Whilst the data for these particular species (Leiodidae beetles) are compelling, the finding seems unlikely to apply more generally to the glacial relict, cold-adapted spiders in our study. These have a rather different evolutionary history to that of the beetles and are not shown to be able to over-express similar, protective proteins. It is clear, however, that 
an intrinsic degree of uncertainty remains associated with interpreting the results of any statistical model of this kind.

Accordingly, as a follow up of this study, we aim to combine multiple lines of evidence (see Peterson 2009, Huey et al. 2012) — such as thermal tolerance experiments and population genetic studies-in order to explore our predicted patterns further (see Krehenwinkel et al. 2015 for an example on spiders). Testing the physiological response of subterranean model species to altered climatic condition could help to identify their specific upper thermal limits, and thus provide experimental evidence for our findings. In parallel, molecular analysis could establish contemporary population structure and dispersal modes, thereby increasing our understanding of the ability of subterranean species to escape and survive climate changes.

\section{Conclusions}

Together with other species living in confined habitats such as islands (e.g., Bellard et al. 2014, Yalor and Kumar 2016) and mountain summits (e.g., Beniston 2003, Xu et al. 2009, Yoccoz et al. 2010), we expect cave adapted species to be as vulnerable, if not more so, to climate change. However, the principal mechanisms underlying the response of cave-dwelling species to global climate change are as yet poorly described. Caves are excellent natural laboratories for the study of global changes in environment because of their remarkable ecological and thermal stability. Our findings emphasized the importance of considering subterranean organisms as model species for ecological studies dealing with climatic changes, and to extend such investigations to other subterranean systems worldwide.

\section{Authors contribution statement}

MI and SM conceived the study, collected and analyzed the data. SLG provided fundamental arguments for the discussion. All authors contributed to the writing of the manuscript.

\section{Acknowledgments}

'This article is protected by copyright. All rights reserved.' 
This work is part of the work package 6 (WP6) of the CAVELAB project "From microclimate to climate change: caves as laboratories for the study of the effects of temperature on ecosystems and biodiversity", funded by Compagnia di San Paolo and University of Turin-Progetti di Ricerca di Ateneo 2011, cod. ORTO11T92F. We are indebted to Giovanni Badino for providing physical argumentations about subterranean meteorology and to all the people involved in CAVELAB. A special thank goes to Mauro Paschetta and Enrico Lana, for helping us place and retrieve several I-button devices. We warmly thank the graphic designer Irene Frigo, for helping us to create the graphical abstract. We are grateful to Lise Comte, Boris Leroy and an anonymous reviewer for their help in improving the quality of the manuscript through their constructive comments during the review process. 


\section{Literature cited}

Allouche, O. et al. 2006. Assessing the accuracy of species distribution models: prevalence, kappa and the true skill statistic (TSS). - J. Appl. Ecol. 43: 12231232.

AGSP 2016. Catasto speleologico del Piemonte e della Valle D'Aosta. - Associazione Gruppi Speleologici Piemontesi, Italy, < http://sellarenato.interfree.it >.

Badino, G. 2004. Cave temperature and Global Climatic Change. - Int. J. Speleol. 33: $103-114$.

Badino, G. 2010. Underground meteorology. What's the weather underground? - Acta Carsol. 39: 427-448.

Barve, N. et al. 2011. The crucial role of the accessible area in ecological niche modeling and species distribution modeling. - Ecol. Model. 222: 1810-1819.

Beaumont, L. J. et al. 2008. Why is the choice of future climate scenarios for species distribution modelling important? - Ecol. Lett. 11: 1135-1146.

Bellard, C. et al. 2012. Impacts of climate change on the future of biodiversity. - Ecol. Lett. 15: 365-377.

Bellard, C. et al. 2014. Impact of sea level rise on the 10 insular biodiversity hotspots. Global Ecol. Biogeogr. 23: 203-212. 
Beniston, M. 2003. Climatic change in mountain regions: a review of possible impacts. - Springer.

Bernabò, P. et al. 2011. Cold stenothermal cave-dwelling beetles do have an HSP70 heat shock response. - J. Therm. Biol. 36: 206-208.

Botosaneanu, L. and Holsinger, J. 1991. Some aspects concerning colonization of the subterranean realm - especially subterranean waters: a response to Rouch and Danielopol, 1987. - Stygologia 6: 11-39.

Brandmayr, P. et al. 2013. Hypogean carabid beetles as indicators of global warming? Env. Res. Lett. 8: 1-11.

Brignoli, P. M. 1971. Note su ragni cavernicoli italiani (Araneae). - Fragm. Entomol. 7: $129-229$.

Bryson, Jr R. W. et al. 2014. Caves as microrefugia: pleistocene phylogeography of the troglophilic North American scorpion Pseudouroctonus reddelli. - BMC Evol. Biol. 14: 9.

Cardoso, P. 2012. Diversity and community assembly patterns of epigean vs. troglobiont spiders in the Iberian Peninsula. - Int. J. Speleol. 41(1): 83-94.

Cardoso, P. et al. 2011a. Adapting the IUCN red listing criteria for invertebrates. - Biol. Conserv. 144: 2432-2440. 
Cardoso, P. et al. 2011b. The seven impediments in invertebrate conservation and how to overcome them. - Biol. Conserv. 144: 2647-2655.

Chen, I. C. et al. 2011. Rapid range shifts of species associated with high levels of climate warming. - Science 333(6045): 1024-1026.

Chevaldonné, P. and Lejeune, C. 2003. Regional warming-induced species shift in northwest Mediterranean marine caves. - Ecol. Lett. 6: 371-379.

Christman, M. C. et al. 2016. Predicting the occurrence of cave-inhabiting fauna based on features of the earth surface environment. - PloS ONE 11: e0160408.

Cooper-Bohannon, R. et al. 2016. Predicting bat distributions and diversity hotspots in southern Africa. - Hystrix 27.

Covington, M. D. and Perne, M. 2015. Consider a cylindrical cave: a physicist's view of cave and karst science. - Acta Carsol. 44: 363-380.

Culver, D.C. and Pipan, T. 2009. The Biology of Caves and other Subterranean Habitats. - Oxford Univ. Press.

Culver, D.C. and Pipan, T. 2010. Climate, abiotic factors, and the evolution of subterranean life. - Acta Carsol. - 39: 539-577.

Dawson, T. P. et al. 2011. Beyond predictions: biodiversity conservation in a changing climate. - Science 332: 53-58. 
Deeleman-Reinhold, C. L. 1978. Revision of the cave-dwelling and related spiders of the genus Troglohyphantes Joseph (Linyphiidae), with special reference to the Jugoslav species. Opera Academia Scientiarum et Artium Slovenica.

Delay, B. 1978. Milieu souterrain et écophysiologique de la reproduction et du développement des Coléoptères Bathysciinae hypogés. - Mém. Biospéol. 5: 1349.

Diniz-Filho, J. A. F. et al. 2009. Partitioning and mapping uncertainties in ensembles of forecasts of species turnover under climate change. - Ecography 32: 897-906.

Domìnguez-Villar, D. et al. 2015. Is global warming affecting cave temperatures? Experimental and model data from a paradigmatic case study. - Clim. Dynam. 45: 569-581.

Ehlers, J. et al. 2011. Quaternary glaciations - extent and chronology. A closer look. Vol. 15. - Elsevier.

Elith, J. and Graham, C. H. 2009. Do they? How do they? WHY do they differ? On finding reasons for differing performances of species distribution models. Ecography 32: 66-77.

Elith, J. et al. 2006. Novel methods improve prediction of species' distributions from occurrence data. - Ecography 29: 129-151. 
Ferreira, M. I. et al. 2016. The genus Zelurus Hahn, 1826, in Brazilian caves: description of new species and comments on the potential distribution of the genus in South America. - Zootaxa 4170: 250-270.

Fejér, A. and Moldovan, O. T. 2013 Population size and dispersal patterns for a Drimeotus (Coleoptera, Leiodidae, Leptodirini) cave population. - Subterr. Biol. 11: $31-44$

Fielding, A. H. and Bell, J. F. 1997. A review of methods for the assessment of prediction errors in conservation presence/absence models. - Environ. Cons. 24: $38-49$.

Fišer, Ž. et al. 2015. Morphologically cryptic amphipod species are "ecological clones" at regional but not at local scale: a case study of four Niphargus species. - PloS ONE 10(7): e0134384.

Friedman, J. H. 2001. Greedy function approximation: a gradient boosting machine. Ann. Stat. 29: 1189-1232.

Gittleman, J. L. and Kot, M. 1990. Adaptation: statistics and a null model for estimating phylogenetic effects. - Syst. Zool. 39: 227-241.

Hedin, M. C. 1997. Molecular phylogenetics at the population/species interface in cave spiders of the southern Appalachians (Araneae: Nesticidae: Nesticus). - Mol. Biol. Evol. 14: 309-324. 
Hijmans, R. J. et al. 2005. Very high resolution interpolated climate surfaces for global land areas. - Int. J. Climatol. 25: 1965-1978.

Ho, Y. C. and Pepyne, D. L. 2002. Simple explanation of the no-free-lunch theorem and its implications. - J. Optim. Theory Appl. 115: 549-570.

Holsinger, J. R. 1988. Troglobites: the evolution of cave-dwelling organisms. - Am.

Sci. 76: 147-153.

Howarth, F. G. 1980. The Zoogeography of specialized cave animals: a bioclimatic model. - Evolution 34: 394-406.

Huey, R. B. et al. 2012. Predicting organismal vulnerability to climate warming: roles of behaviour, physiology and adaptation. - Phil. Trans. R. Soc. B 367: 16651679.

Huevy, R. B. and Kingsolver, J. G. 1989. Evolution of thermal sensitivity of ectotherm performance. - Trends Ecol. Evol. 4: 131-135.

Hurvich, C. M. and Tsai C. L. 1989. Regression and time series model selection in small samples. - Biometrika 76: 297-307.

IPCC 2014. Climate Change 2014: Synthesis Report. Contribution of Working Groups I, II and III to the Fifth Assessment Report of the Intergovernmental Panel on Climate Change. - IPCC. 
Isaia, M. and Pantini, P. 2010. New data on the spider genus Troglohyphantes (Araneae, Linyphiidae) in the Italian Alps, with the description of a new species and a new synonymy. - Zootaxa 2690: 1-18.

Isaia, M. et al. 2011. Subterranean arachnids of the Western Italian Alps (Arachnida: Araneae, Opiliones, Palpigradi, Pseudoscorpiones). - Mon. Mus. Reg. Sc. Nat.

Isaia, M. et al. 2017. Advances in the systematics of the spider genus Troglohyphantes (Araneae, $\quad$ Linyphiidae). $\quad-\quad$ Syst. $\quad$ Biodivers., $\quad$ doi $10.1080 / 14772000.2016 .1254304$

Juberthie, C. and Decou, V. 1994. Structure et diversité du domaine souterrain; particularités des habitats et adaptations des espèces. - Encycl. Biospeol. 1: 522.

Kageyama, M. et al. 2001. The Last Glacial Maximum climate over Europe and western Siberia: a PMIP comparison between models and data. - Clim. Dynam. 17: 2343.

Krehenwinkel, H. et al. 2015. Eco-Genomic analysis of the poleward range expansion of the wasp spider Argiope bruennichi shows rapid adaptation and genomic admixture. - Glob. Change Biol. 21: 4320-4332.

Lencioni, V. et al. 2010. Cold resistance in two species of cave-dwelling beetles (Coleoptera: Cholevidae). - J. Therm. Biol. 35: 354-359. 
Mammola, S. and Isaia, M. 2016. The ecological niche of a specialized subterranean spider. - Invertebr. Biol. 135: 20-30.

Mammola, S. et al. 2015a. Alpine endemic spiders shed light on the origin and evolution of subterranean species. - PeerJ 3: e1384.

Mammola, S. et al. 2015b. Seasonal dynamics and micro-climatic preference of two Alpine endemic hypogean beetles. - Int. J. Speleol. 44: 239-249.

Mammola, S. et al. 2016. Ecology and sampling techniques of an understudied subterranean habitat: the Milieu Souterrain Superficiel (MSS). - The Science of Nature 103(11-12): 88.

McCullagh, P. and Nelder, J. A. 1989. Generalized Linear Models (2nd ed.). Chapman and Hall.

Mermillod-Blondin, F. et al. 2013. Thermal tolerance breadths among groundwater crustaceans living in a thermally constant environment. - J. Exp. Biol. 216: $1683-1694$.

Merow, C. et al. 2013. A practical guide to MaxEnt for modeling species' distributions: what it does, and why inputs and settings matter. - Ecography 36: 1058-1069.

Moore, G. W. and Sullivan, G. N. 1964. Out of phase seasonal temperature fluctuations in Cathedral Cave, Kentucky. - Geol. Soc. Am. 76: 313. 
Motta, M. 2014. The definition of the extension of quaternary glaciers within alpine valleys, and his application to study of troglobites. - EDIS 1: 439-444.

Naranjo, M. et al. 2014. ¿Dónde buscar troglobiontes? Ensayo de una cartografía predictiva con MaxEnt en Gran Canaria (islas Canarias). - Arxius de Miscellània Zoològica 12: 83-92.

Newbold, T. 2010. Applicatons and limitatons of museum data for conservaton and ecology, with particular attention to species distribution models. - Prog. Phys. Geog. 34: 3-22.

Novak, T. et al. 2014. Cold tolerance in terrestrial invertebrates inhabiting subterranean habitats. - Int. J. Speleol. 43: 265-272.

Paradis, E. et al. 2004. APE: analyses of phylogenetics and evolution in R language. Bioinformatics 20: 289-290.

Parmesa, C. and Yohe, G. 2003. A globally coherent fingerprint of climate change impacts across natural systems. - Nature 421: 37-42.

Parmesan, C. 2006. Ecological and evolutionary responses to recent climate change. Annu. Rev. Ecol. Evol. Syst.: 637-669.

Peterson, A. T. 2009. Phylogeography is not enough: the need for multiple lines of evidence. - Front. Biogeogr. 1: 19-25. 
Peterson, A. T. et al. (2011) Ecological niches and geographical distributions: a modeling perspective. - Princeton Univ. Press.

Phillips, S. J. et al. 2006. Maximum entropy modeling of species geographic distributions. - Ecol. Model. 190: 231-259.

Phillips, S. J. 2009. Sample selection bias and presence-only distribution models: implications for background and pseudo-absence data. - Ecol. Appl. 19: 181197.

Phillips, S. J. 2011. A brief tutorial on Maxent. - AT\&T Research, Princeton.

Poulson, T. L. and White, W. B. 1969. The cave environment. - Science 165: 971-981.

Qiao, H. et al. 2015. No silver bullets in correlative ecological niche modelling: insights from testing among many potential algorithms for niche estimation. - Methods Ecol. Evol. 6: 1126-1136.

R Development Core Team 2015. R: A language and environment for statistical computing. - R Foundation for Statistical Computing, Austria, < http://www.Rproject.org/ >.

Rizzo, V. et al. 2015. Lack of evolutionary adjustment to ambient temperature in highly specialized cave beetles. - BMC Evol. Biol. 15: 10.

Romero, A. 2009. Cave biology. - Cambridge Univ. Press. 
Rouch, R. and Danielpol, D. 1987. L'origine de la faune aquatique souterraine, entre le paradigme du refuge et le modèle de la colonisation active. - Stygologia 3: 345372.

Rull, V. 2009. Microrefugia. - J. Biogeogr. 36: 481-484.

Sánchez-Fernández, D. et al. 2016. Thermal niche estimators and the capability of poor dispersal species to cope with climate change. - Sc. Rep. 6: 23381.

Saupe, E. E. et al. 2012. Variation in niche and distribution model performance: the need for a priori assessment of key causal factors. - Ecol. Model. 237: 11-22.

Smithson, A. 1991. Inter-relatonships between cave and outside air temperatures. Theor. Appl. Climatol. 44: 65-73.

Snowman, C. V. et al. 2010. Caves as islands: mitochondrial phylogeography of the cave-obligate spider species Nesticus barri (araneae: Nesticidae). - J. Arachnol. 38: 49-56.

Soto-Centeno, J. A. et al. 2015. The importance of late Quaternary climate change and karst on distributions of Caribbean mormoopid bats. - Am. Mus. Novit. 3847: $1-32$.

Syfert, M. M. et al. 2013. The effects of sampling bias and model complexity on the predictive performance of MaxEnt Species Distribution Models. - PLoS ONE 8: e55158. 
Taylor, S. and Kumar, L. 2016. Global climate change impacts on pacific islands terrestrial biodiversity: a review. - Trop. Conserv. Sci. 9: 203-223.

Taylor, K. E. et al. 2012. An overview of CMIP5 and the experiment design. - B. Am. Meteorol. Soc. 93: 485-49.

Walther, G. R. 2010. Community and ecosystem responses to recent climate change. Phil. Trans. R. Soc. Lond., B, Biol. Sci. 365: 2019-2024.

Walther, G. R. et al. 2002. Ecological responses to recent climate change. - Nature 416: 389-395.

Wynne, J.J. et al. 2014. Disturbance relicts in a rapidly changing world: The Rapa Nui (Easter Island) factor. - Bioscience 64: 711-718.

$\mathrm{Xu}$, J. et al. 2009. The melting Himalayas: cascading effects of climate change on water, biodiversity, and livelihoods. - Conserv. Biol. 23: 520-530.

Yao, Z. et al. 2016. High endemism at cave entrances: a case study of spiders of the genus Uthina. - Sc. Rep., 6: 35757.

Yoccoz, N. G. et al. 2010. Impact of climatic change on alpine ecosystems: inference and prediction. - J. Alp. Res.: 98-104. 
Zimmermann, N. E. et al. 2009. Climatic extremes improve predictions of spatial patterns of tree species. - Proc. Natl. Acad. Sc. USA 106: 19723-19728.

Zuur, A. F. et al. 2010. A protocol for data exploration to avoid common statistical problem. - Methods Ecol. Evol. 1: 3-14.

Zuur, A. F. et al. 2009. Mixed effect models and extensions in ecology with R. Springer. 


\section{Table Legend}

Table 1. List of the variables selected to construct the regional scale model. The uncorrelated variables (Pearson $r< \pm 0.7$ ) used in the model are highlighted. Percent contribution and permutation importance (sensu Phillips 2011) of each variable for building the final MaxEnt model is reported.

\begin{tabular}{|c|c|c|c|c|}
\hline $\begin{array}{c}\text { Variabl } \\
\text { e }\end{array}$ & Description & Unit & $\begin{array}{c}\text { Percent } \\
\text { contribution }\end{array}$ & $\begin{array}{l}\text { Permutation } \\
\text { importance }\end{array}$ \\
\hline Bio01 & Annual Mean Temperature & ${ }^{\circ} \mathbf{C}$ & $29.6 \%$ & 27.4 \\
\hline Bio02 & Mean Diurnal Range & ${ }^{\circ} \mathbf{C}$ & $32.7 \%$ & 32.5 \\
\hline Bio03 & $\begin{array}{l}\text { Isothermality (Bio02/Bio07) } \\
(* 100)\end{array}$ & ${ }^{\circ} \mathrm{C}$ & - & \\
\hline Bio04 & $\begin{array}{l}\text { Temperature Seasonality } \\
\text { (standard deviation*100) }\end{array}$ & ${ }^{\circ} \mathrm{C}$ & - & \\
\hline Bio05 & $\begin{array}{l}\text { Max Temperature of Warmest } \\
\text { Month }\end{array}$ & ${ }^{\circ} \mathrm{C}$ & - & \\
\hline Bio06 & $\begin{array}{l}\text { Min Temperature of Coldest } \\
\text { Month }\end{array}$ & ${ }^{\circ} \mathrm{C}$ & - & \\
\hline Bio07 & $\begin{array}{l}\text { Temperature Annual Range } \\
\text { (Bio05-Bio06) }\end{array}$ & ${ }^{\circ} \mathrm{C}$ & & \\
\hline Bio08 & $\begin{array}{l}\text { Mean Temperature of Wettest } \\
\text { Quarter }\end{array}$ & ${ }^{\circ} \mathrm{C}$ & - & \\
\hline Bio09 & $\begin{array}{l}\text { Mean Temperature of Driest } \\
\text { Quarter }\end{array}$ & ${ }^{\circ} \mathrm{C}$ & Discarded $(<5 \%)$ & Discarded \\
\hline Bio10 & Mean Temperature of Warmest & ${ }^{\circ} \mathrm{C}$ & - & \\
\hline
\end{tabular}




\begin{tabular}{|c|c|c|c|c|}
\hline $\begin{array}{l}\text { Variabl } \\
\text { e }\end{array}$ & Description & Unit & $\begin{array}{c}\text { Percent } \\
\text { contribution }\end{array}$ & $\begin{array}{l}\text { Permutation } \\
\text { importance }\end{array}$ \\
\hline & Quarter & & & \\
\hline Bio11 & $\begin{array}{l}\text { Mean Temperature of Coldest } \\
\text { Quarter }\end{array}$ & ${ }^{\circ} \mathrm{C}$ & - & \\
\hline Bio12 & Annual Precipitation & $\mathrm{mm}$ & - & \\
\hline Bio13 & Precipitation of Wettest Month & $\mathrm{mm}$ & - & \\
\hline Bio14 & Precipitation of Driest Month & $\mathrm{mm}$ & - & \\
\hline Bio15 & $\begin{array}{l}\text { Precipitation Seasonality } \\
\text { (Coefficient of Variation) }\end{array}$ & $\mathrm{mm}$ & - & \\
\hline Bio16 & Precipitation of Wettest Quarter & $\mathrm{mm}$ & - & \\
\hline Bio17 & Precipitation of Driest Quarter & $\mathrm{mm}$ & - & \\
\hline Bio18 & $\begin{array}{l}\text { Precipitation of Warmest } \\
\text { Quarter }\end{array}$ & $\mathbf{m m}$ & Discarded $(<5 \%)$ & Discarded \\
\hline Bio19 & Precipitation of Coldest Quarter & $\mathrm{mm}$ & - & \\
\hline Alt & Altitude a.s.l & $\mathrm{m}$ & - & \\
\hline Ice & $\begin{array}{l}\text { Ice cover during Last Glacial } \\
\text { Maximum }\end{array}$ & $\begin{array}{l}\text { Categ } \\
\text { orical }\end{array}$ & $37.7 \%$ & 40.1 \\
\hline
\end{tabular}




\section{Figure Legends}

Figure 1. Hypogean localities selected in the present work. Ice cover during Last Glacial

Maximum is reported in the top-right inset map. A code in brackets referring to the

Italian speleological cadaster is provided for each locality-more details in

Supplementary Material Appendix 1.

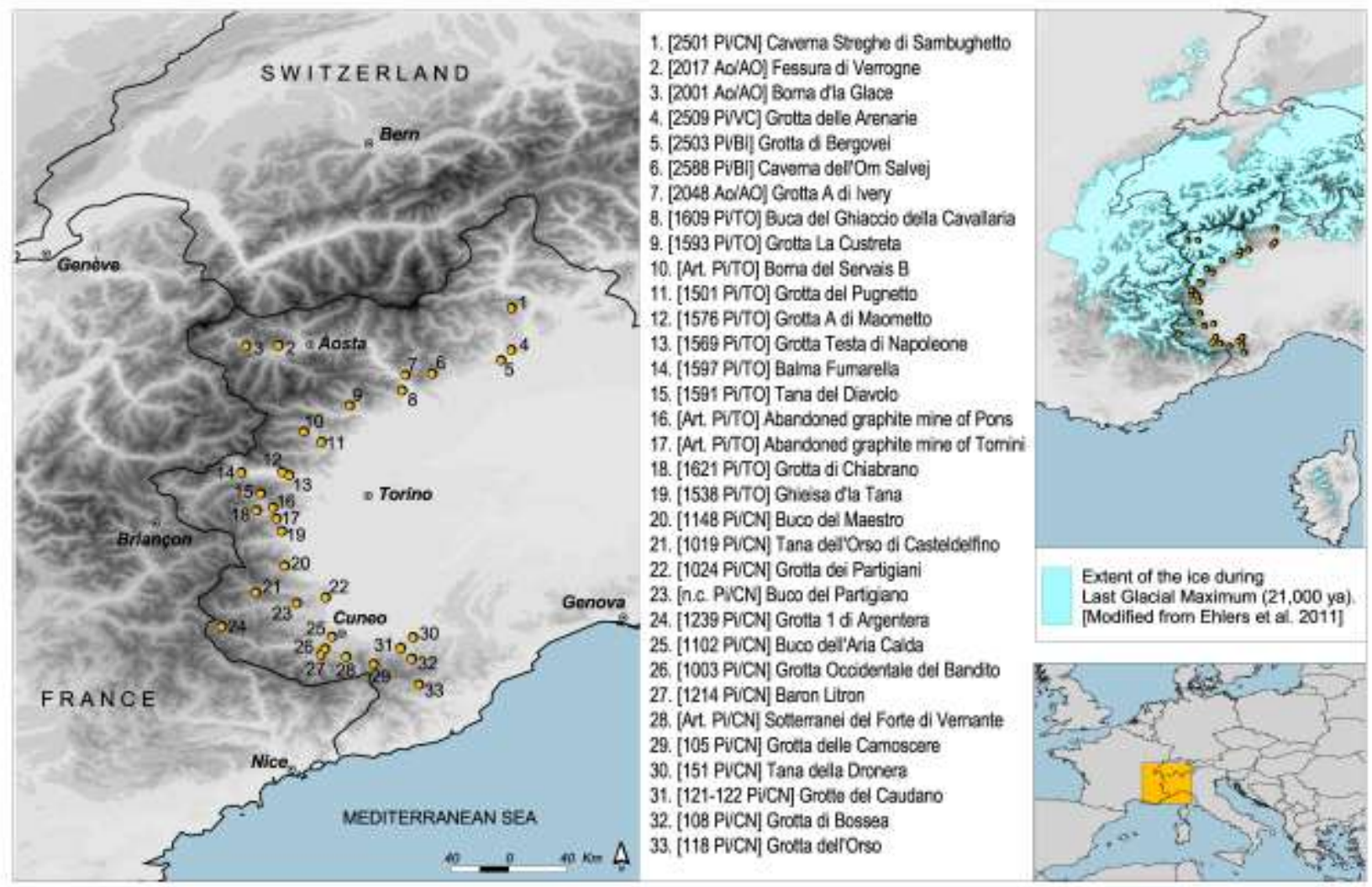

'This article is protected by copyright. All rights reserved.' 
Figure 2. Predicted values (filled lines) and 95\% confidence intervals (dashed lines) of the effect of mean annual cave temperature $\left(\mathrm{T}_{\mathrm{int}}\right)$ on the probability of presence of Troglohyphantes spiders according to glacial history, derived from GLM analysis.

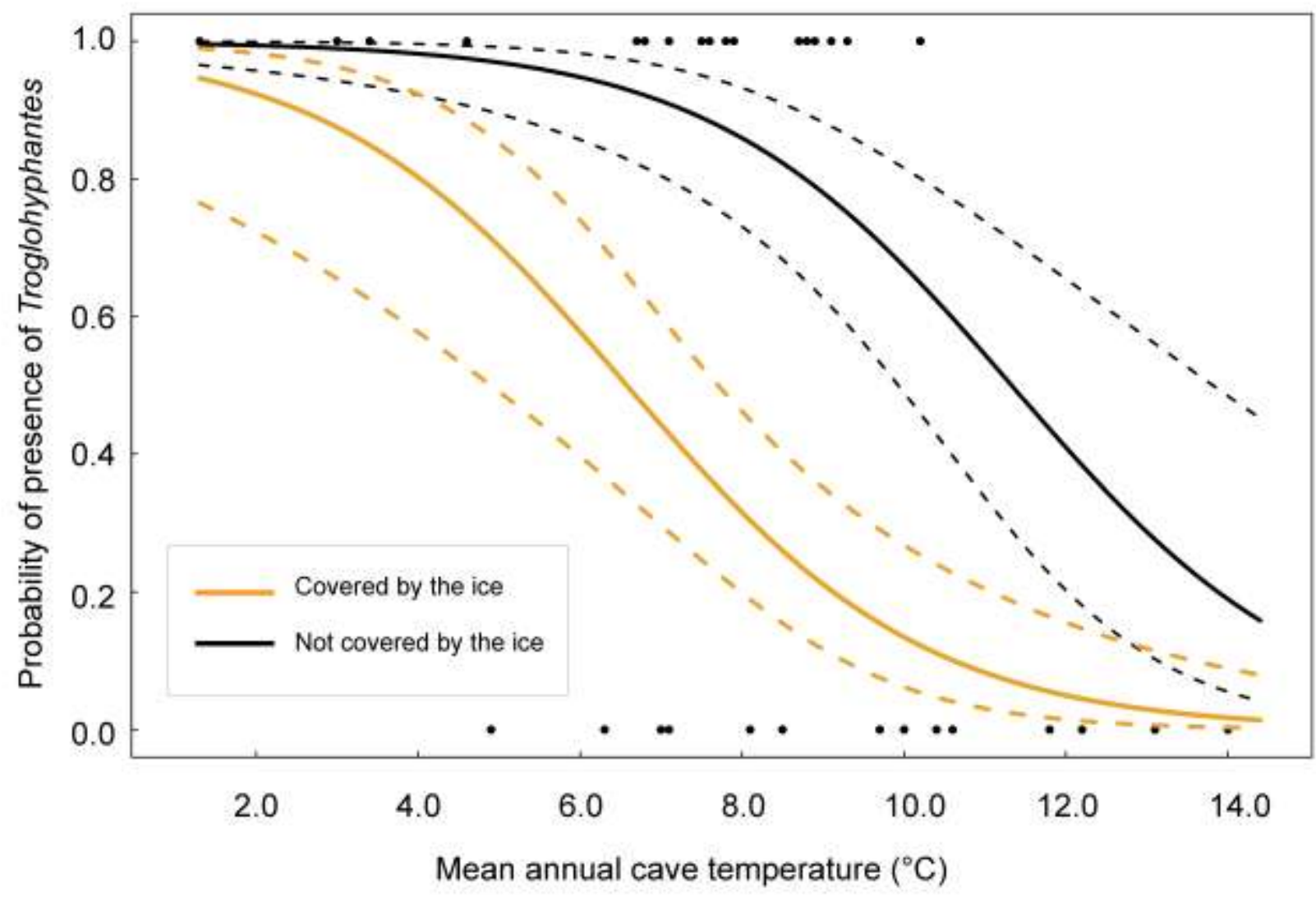


Figure 3. Projected habitat suitability of Western Alps for troglobiomorphic species of Troglohyphantes spiders according to current and Last Glacial Maximum (LGM) climatic conditions. LGM projection represents the average model outputs from three General Circulation Models (GCMs). Only suitable habitat over the threshold of 0.4 are shown.

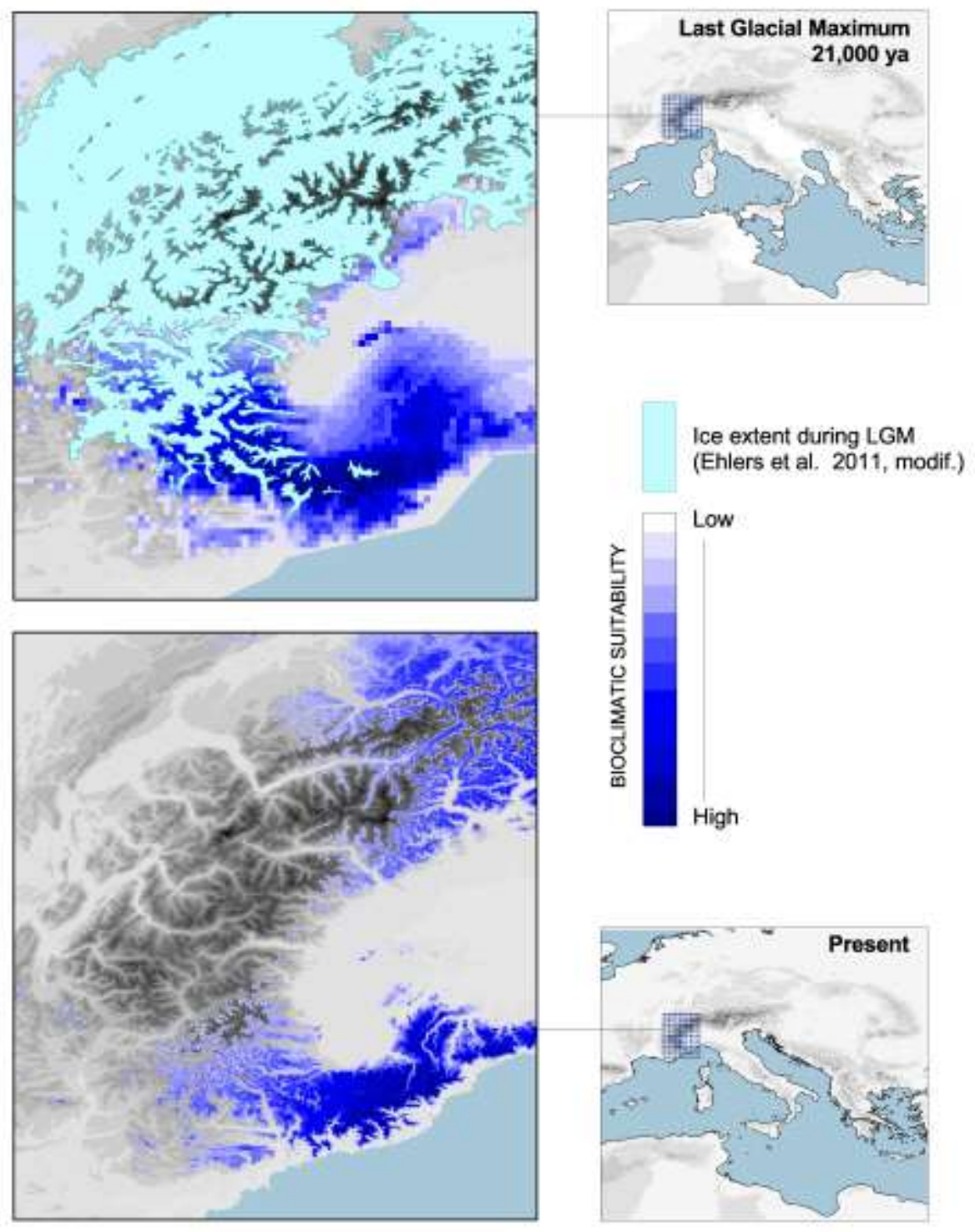


Figure 4. Projected future habitat suitability of the Western Alps for troglobiomorphic species of Troglohyphantes spiders in 2050 and 2070 according to the two Representative Concentration Pathways (rcp) considered in the work. Only suitable habitat over the threshold of 0.4 are shown.

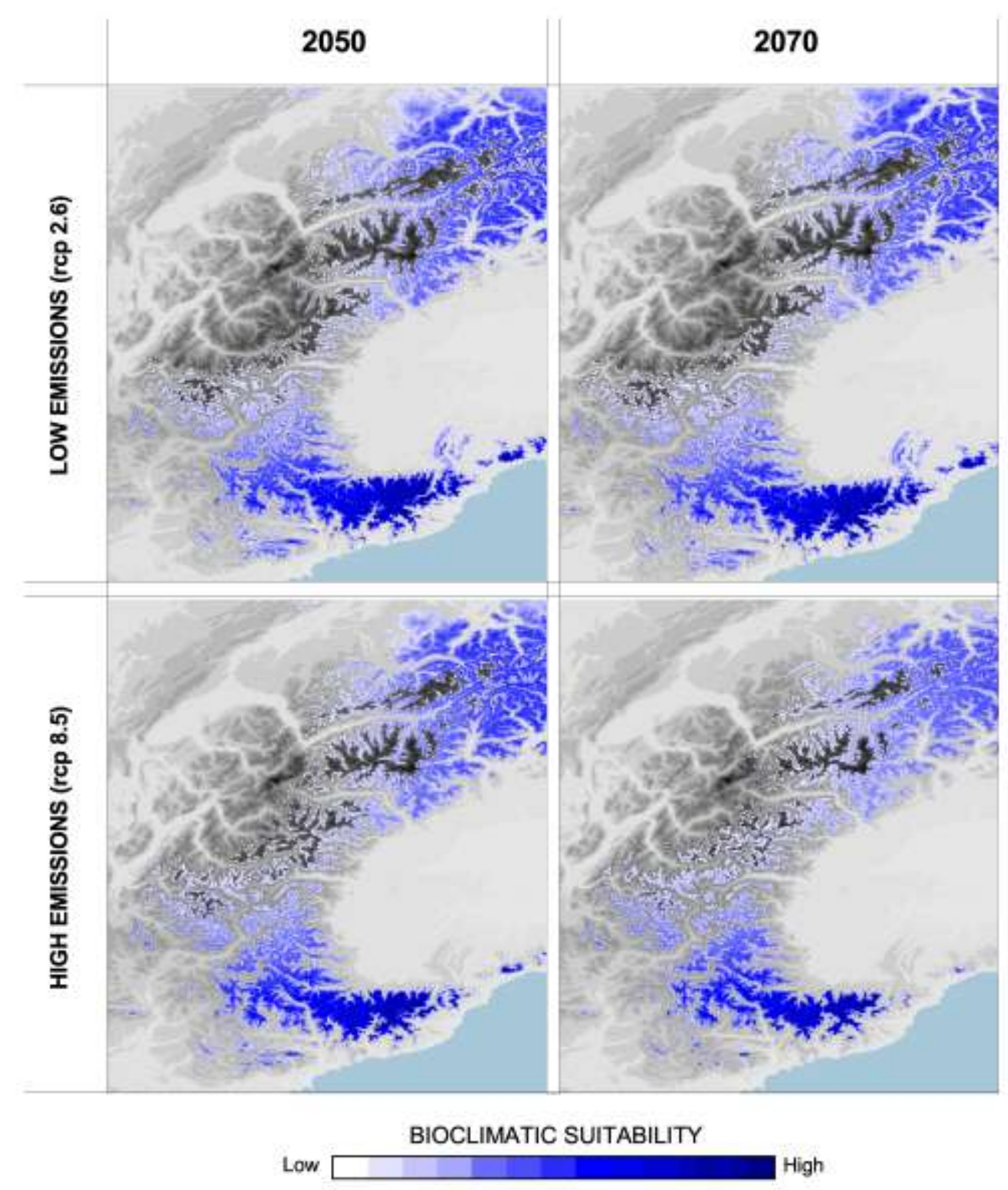

'This article is protected by copyright. All rights reserved.' 

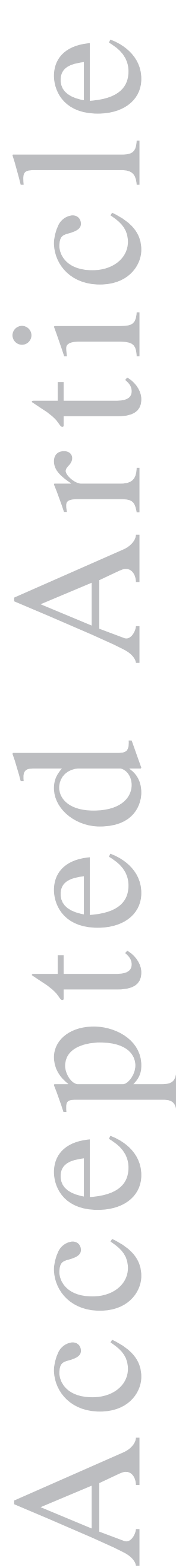

'This article is protected by copyright. All rights reserved.' 
Figure 5. Current and projected future habitat suitability (high emissions scenario for 2070) of the Western Alps for Troglohyphantes spiders. Orange dots represent current localities of Troglohyphantes. Localities of T. lucifuga and T. lucifer are not shown in the map. Only suitable habitat over the threshold of 0.4 are shown (rescaled $0-1$ ).

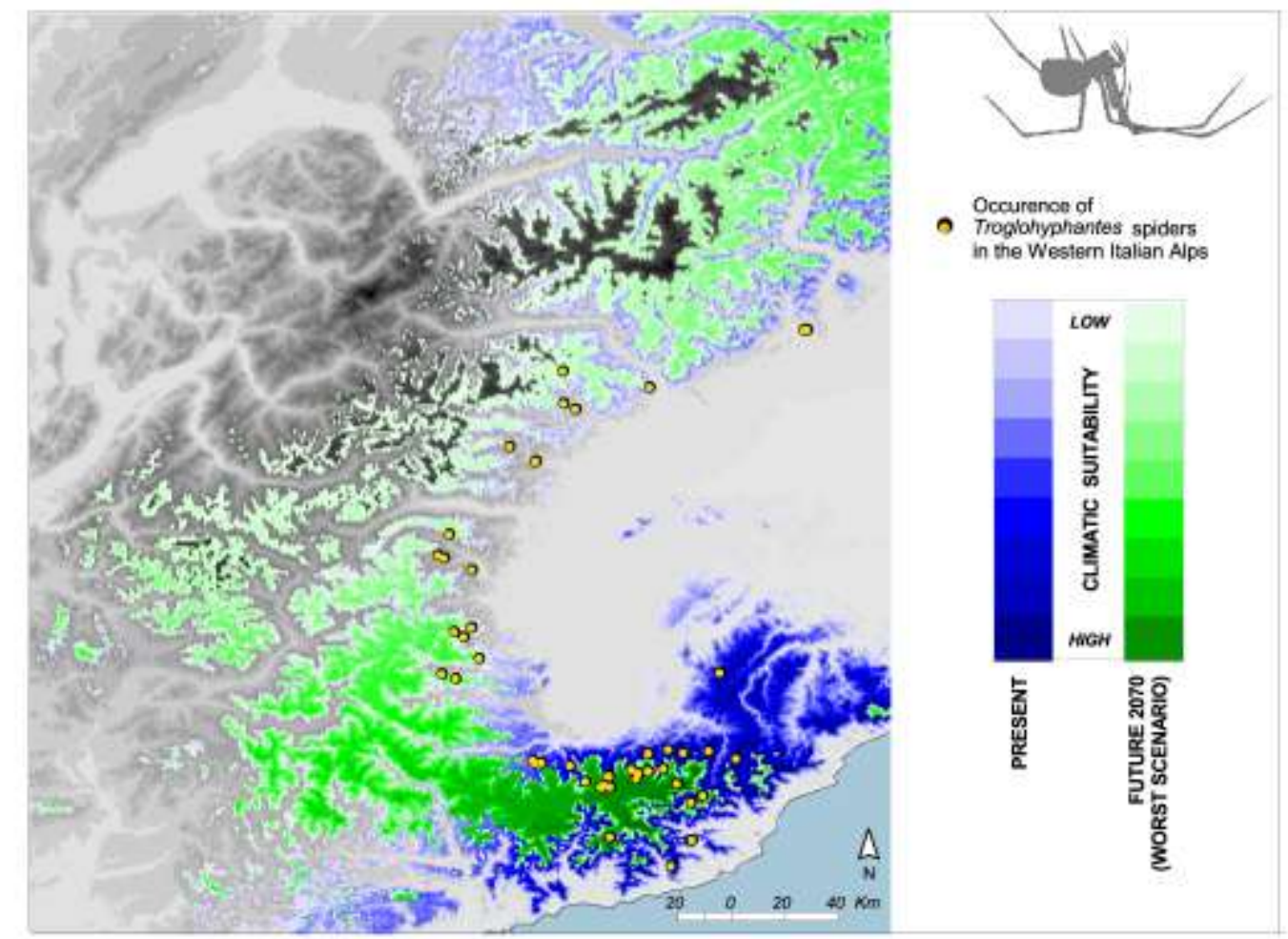

